items before mentioned, I thought I should certainly be doing them (the New Yorkers) a benefit by explaining to them the many advantages of the screw over the side wheel, thereby saving them thousands of dollars, and benefiting society in general. I therefore informed them that, with equal power, a screw vessel would cost less money, carry more freight, and go faster at all times; and that, with head winds and heavy weather, the propeller was much superior. These facts I enforced with all the ability I possessed, and all good men will allow that my exertions merited some reward. But you may judge of my astonishment when told by them that I was behind the times, that propellers might do where money was scarce and speed no object, but for a city that had money, enterprise, and goaheadativeness, screws were too slow, the machinery made too much noise, from its high velocity, and as for speed, their side wheel steamers could easily beat our propellers at any time, and in head winds, with heavy sea, a propeller was not good for much; that our "Columbus" was often seen beating at sea, (when the wind was ahead,) like a ship, and much more of the same tenor, and they finally wound up by saying that they were a humbug compared to side wheels, and pointed to the Cunard Steamers, the New Orleans Steamers, the Chagres Steamers, the Savannah Steamers, the Charleston Steamers, the Bremen Steamers, and to six large side wheel steamers building, and after so doing, asked me what I had to say. Having had my say before hand, and not being prepared for opposition, I immediately came home for further information based on facts, which I now respectfully solicit from the friends of side wheels and propellers.

JoHN JoNes.

\title{
Particulars of the new Iron Steamboat John Neilson, running from $\mathcal{N}$ ew York to $\mathcal{N} e w$ Brunswick.
}

This fine steamer was intended to be the foundation of a new epoch in steam navigation, and has received all the attention that could be bestowed upon her by her builders, the Messrs. Stevens, and it is a source of regret that she does not come up to their expectations.

The novelty in this boat was the forcing through the bottom several jets of air, under a pressure of 3 to 4 pounds to the inch. There were about 75 jets, of different sizes from 1 to 4 inches; each jet had a guard at its mouth, to direct the air aft; the bottom of the boat was flat, and her mid-

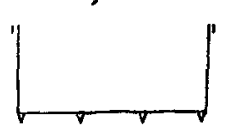
ship section like the annexed sketch, having four projections or keels of 3 inches deep, which were for guiding the air the whole length of the hull, where it escaped at the stern, it being supposed that a grcat advantage would be gained by a decreased draft of water and reduced friction while running. The following are her dimensions:-

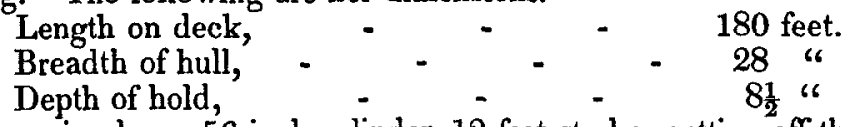

The engine has a 56-inch cylinder, 12 feet stroke, cutting off the steam at 6 I feet. Water wheel, 32 feet diameter and 10 feet face; paddles 28 inches deep; number of revolutions per minute, 20. Two boilers, 14 feet 
6 inches long, 10 feet 7 inches wide, and 8 feet high, each having two furnaces, 7 feet long, and 4 feet 7 inches wide; each furnace has but one lower flue running to the back end of the boiler, and 180 two-inch tubes above, making 360 tubes in each boiler 10 feet long. The furnaces are supplied with air by two blowers, driven by two engines, with cylinders 12 inches in diameter and 12 inches stroke, making 50 revolutions, and geared 6 to 1. The air for the bottom of the boat is forced through by two blowing cylinders, 40 inches in diameter and 4 feet stroke, making 60 double strokes per minute; each cylinder is worked by a steam engine, with cylinder 16 inches in diameter and 4 feet stroke, cutting off at onehalf. All of the engines exhaust into the condenser of the large engine.

The hold, for about 100 feet, is occupied by machinery, which requires an extra number of persons to attend it, and, from the high velocity of some portions, it makes more noise than usual.

In departing from established usage and developing new principles, all persons are likely to err: the enthusiasm connected with the new idea destroying the common sense attached or belonging to the old. 'The Messrs. Stevens have been thus misled, and from some experiments on a canal boat in a canal, which gave them a high result, they immediately projected the "John Neilson," (having first secured the patent,) and promised at least 30 miles per hour, at the same time adopting a model which, at this time, would be considered barbarous by the most ignorant ship-builder in the country. Imagine a boat of the midship section before given, with a lean bow, and a stern to this sketch, the full width being carried aft, similar to a canal boat, and then think of 30 miles per hour. With the

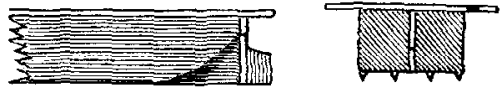
blowing cylinders in operation, the boat makes about 15 miles per hour, and the large engine will make $1 \frac{1}{2}$ more revolutions when the blast is on the bottom than when it is off, while boats of the usual form and equal power will make at least three miles more, from which it is plain that the only gain is a loss, by the new arrangement. But this is only proved a loss so far as the "John Neilson" is concerned, for the air certainly helps her, and they find it advantageous to use it; and if it helps her, would it not assist a boat having as good a model as conld be obtained? I think it would, and I have no doubt, the Messrs. Stevens will be ultimately rewarded with a moderate increase of speed. The projectors of new ideas rarely succeed at first, but $\mathbf{I}$ hope soon to hear of the more perfect development of their plan.

D.

Translated for the Journal of the Franklin Institute.

Method of Determining the Quantity of Phosphoric Acid in Soils by means of a Normal Liquor. By M. E. Cottereau.

This method is based, first, upon the property which solutions of potassa and soda possess of transforming, at the boiling temperature, insoluble phosphates into the soluble phosphates of these bases; and, secondly, upon the property which nitrate of silver possesses of precipitating, at ordinary temperatures, these phosphates, by forming a phosphate of silver whose com- 